\title{
Virtual reality in biology: could we become virtual naturalists?
}

\author{
Juliano Morimoto ${ }^{1 *}$ (B) and Fleur Ponton ${ }^{2}$
}

\begin{abstract}
The technological revolution of past decades has led teaching and learning of evolutionary biology to move away from its naturalist origins. As a result, students' learning experiences and training on the science of natural historywhich entails careful observations and meticulous data curation to generate insight-have been compromised compared with the times of the pioneers in the field. But will technology cause the extinction of natural history in its traditional form? In this essay, we provide a visionary —albeit not yet possible - perspective of the future of natural history in the technological era. We review the main concepts and applications of key state-state-of-the-art technologies to the teaching and learning of Biology including Virtual and Mixed Reality (VMR). Next, we review the current knowledge in artificial life, and describe our visionary model for the future of natural history voyages - the BioVR — which is an immersive world where students can experience evolution in action, and also shape how evolution can occur in virtual worlds. We finish the essay with a cautionary tale as to the known negative sides of using VMR technologies, and why future applications should be designed with care to protect the intended learning outcomes and students' experience. Our aim is to stimulate debates on how new technologies can revolutionise teaching and learning across scenarios, which can be useful for improving learning outcomes of biological concepts in face-to-face, blended, and distance learning programmes.
\end{abstract}

Keywords: Darwinian theory, new technology, evolutionary biology, immersive reality, evolving algorithm

\section{Introduction}

In 1831, Charles Darwin climbed aboard the H.M.S Beagle for a journey that would change his life forever, as well as the course of human knowledge (Sulloway 1982). The voyage, which lasted ca. 5 years, gave the then young naturalist the opportunity to travel through the biology equivalent of space and time, making observations of plants and animals (dead and alive) with different shapes, colours, and behaviours. Darwin collated an impressive amount of natural history data that later formed the principles of evolution by natural selection, which is now considered the foundation for evolutionary biology (for which another naturalist, Alfred Russell

\footnotetext{
*Correspondence: juliano.morimoto@abdn.ac.uk

${ }^{1}$ School of Biological Sciences, University of Aberdeen, Zoology Building, Tillydrone Ave, AB24 2TZ Aberdeen, UK
}

Full list of author information is available at the end of the article
Wallace, also share merit in the discovery through voyages in South America). These and other naturalists had the opportunity that today, very few (if any) people have: the opportunity to travel to remote places that are yet virgin to human influences, spending years meticulously observing and collecting natural history data in order to make sense of how nature works. In our technological era, however, the naturalist approach to science has given way to the ever-faster pace of computers and data generation, all of which are available at our fingertips. As a result of this cultural and technological shift, voyages like the H.M.S Beagle are essentially extinct, and field trips have become shorter (or due to Covid19, absent) and often arranged in sites that have had substantial levels of human management. Consequently, the true 'naturalist spirit' is at risk of being forgotten, which is a danger to current and future students and professionals in the field

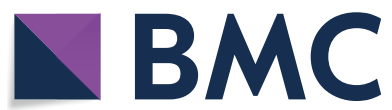

(c) The Author(s) 2021. This article is licensed under a Creative Commons Attribution 4.0 International License, which permits use, sharing, adaptation, distribution and reproduction in any medium or format, as long as you give appropriate credit to the original author(s) and the source, provide a link to the Creative Commons licence, and indicate if changes were made. The images or other third party material in this article are included in the article's Creative Commons licence, unless indicated otherwise in a credit line to the material. If material is not included in the article's Creative Commons licence and your intended use is not permitted by statutory regulation or exceeds the permitted use, you will need to obtain permission directly from the copyright holder. To view a copy of this licence, visit http://creativeco mmons.org/licenses/by/4.0/. The Creative Commons Public Domain Dedication waiver (http://creativecommons.org/publicdomain/ zero/1.0/) applies to the data made available in this article, unless otherwise stated in a credit line to the data. 
of evolutionary biology and, more broadly, to the science of natural history. But could we harness the technological developments of the recent decades to foster-rather than extinguish - the teaching and learning of evolutionary biology akin to the opportunities of the pioneer naturalists of the past? Could we merge the 'old' (natural history) and the 'new' (technology) to revamp and revive the naturalist spirit in the 21st century and beyond? In this essay, we provide a vision for the future of natural history in the technological era, where a combination of recent technologies, global datasets, principles of biological evolution, and pedagogical strategies can converge into a powerful learning tool that creates simulated and immersive worlds to enhance students' learning experiences in evolutionary biology, turning students into naturalist voyagers of the future. To achieve this, we first review the main concepts and applications of key statestate-of-the-art technologies to the teaching and learning of Biology, including Virtual and Mixed Reality (VMR) as well as Machine Learning and Artificial Intelligence (ML and AI, respectively) pertaining to our perspective (a full review of ML and AI is beyond the scope of this essay and can be found elsewhere e.g. Brunette et al. 2009; Kotsiantis et al. 2006). Next, we review the current developments in the field of artificial life through computer simulations, which provide a useful stepping-stone to our visionary model for the future of natural history voyages-the BioVR. We then explain our vision for the BioVR concept, which is an immersive world where students can experience evolution in action, and also shape how evolution can occur in virtual worlds, with benefits for students' learning experiences. Finally, we also provide a cautionary tale as to the known negative impacts of using VMR technologies, and why future applications of VMR (including the BioVR) should be designed with awareness of the intended learning outcomes. Although the BioVR learning tool is not currently possible, we believe much of the knowledge and technology necessary for its conceptualisation exist, bringing us closer to the realization of this vision, which will help improve teaching and learning of evolutionary biology and keep the naturalist spirit of the pioneers in the field alive through technological revolutions.

\section{Virtual and mixed reality (VMR)}

With increasing computational power, technologies that were costly or impossible to implement in the past have now become accessible in laptops and mobile phones (Kish 2004; Waldrop 2016). These technologies are now revolutionising the ways we interact with the world, how we learn, and how we teach (Veletsianos 2010). Virtual and Mixed Reality (VMR, see Fig 1 for terminology) is one of these technologies which has gained increasing attention in the academic and teaching communities (Mazuryk and Gervautz 1996). In fact, over the last decade, there has been an exponential increase in the publication of papers in topics involving Virtual and Mixed Reality in Education (Fig. 2a). VMR can be defined as an alternate world filled with computer-generated entities that interact with human sensory and motor systems to cause a sense of 'presence' (psychological state) in the subject through the use of an 'immersive' technology (i.e., technology that simulates an environment that is not necessarily real) (Yoh 2001). Presence can be defined as 'a state of dissociation from reality in which people feel the subjective experience of existing in the digital environment (Slater 2003).' Although presence and immersion have been used interchangeably (Barbot and Kaufman 2020), experiences that increase presence do not necessarily increase immersive feelings, and vice versa (see meta-analysis by Cummings and Bailenson 2016), suggesting that, although these terms refer to the feeling of 'being there', they are not necessarily equivalent. Nevertheless, both are important in VMR applications. According to the Oxford dictionary, Virtual Reality is defined as 'images and sounds created by a computer that seem almost real to the user, who can interact with them by using sensors', which highlights that presence and immersion are key aspects of virtual reality (see e.g., Lombart et al. 2020). Note that here, Virtual Reality refers to both the hardware (i.e., headsets) but also more broadly, to the technology (of which headsets are a part); our working definition of Virtual Reality in this paper focuses on the latter. According to the taxonomy of Milgram et al. (1995), immersive experiences are achieved through a complex continuum in reproduction fidelity of both the real and virtual environments, whereby the limitations of approaches as well as hardware (e.g., devices and displays) can influence the degree of immersive experience and presence available to the user (Milgram et al. 1995). Note, however, that the feeling of presence and immersion may not necessarily be the ultimate goal of VMR technologies (Milgram et al. 1995; but see Robinett 1992; Sheridan 1992), although the increasingly more realistic displays can eventually result in one feeling complete immersion and presence (Naimark 1991).

VMR has been around for decades, and it is thought to have its origin in the 1960s when Morton Heilig created one of the first immersive multi-sensory simulators that included stimuli such as sound, scent, wind and vibration (called 'Sensorama') (Heilig 1962; Mazuryk and Gervautz 1996). Ever since, VR technology has advanced significantly to the point that today many platforms exist for creating as well as experiencing VMR applications (e.g., Jerald et al. 2014; Ledermann and Schmalstieg 2005; Wexelblat 2014). In the 


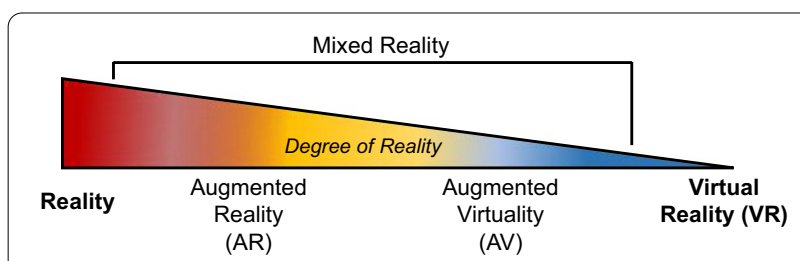

Fig. 1 The reality-virtuality continuum. AR —augmented reality; AV-augmented virtuality; VR - virtual reality [based on (Milgram et al. 1995)]. In a highly influential paper, Milgram, Takemura, Utsumi, and Kishino (1995) proposed the reality-virtuality continuum to classify Virtual, Augmented, and Mixed reality technologies. On one side of the spectrum is the real world (reality) and, on the other side of the spectrum, the fully virtual world (virtuality) where Virtual Reality (VR) in its strict sense resides. In between the extremes, stands Augmented Reality (AR) — which relies mostly on real world elements but with the addition of virtual entities; the best known (and controversial) example of AR has been Pokemon Go! (Serino et al. 2016; Zsila et al. 2018)_and Augmented Virtuality (AV) with the opposite of AR, that is, mostly virtual world but with the addition of 'real' entities. AR and AV are cases of Mixed Reality (MR), where real and virtual elements are intertwined within the application. For the purpose of this paper and for simplicity, we refer to $A R, A V$, and $V R$ all as virtual and mixed reality (VMR) applications because they all have some degree of virtual components introduced into the application

last decade, the use of VMR in teaching and learning has increased dramatically and spans a variety of subjects (Davies et al. 2019; Hoffman and Vu 1997; Makransky et al. 2016; Mikropoulos and Natsis 2011), including biology (Makransky et al. 2016; Shim et al. 2003; Shim et al. 2000). A meta-analysis of sixteen studies has shown that VMR surgical simulators decrease the time to complete surgical procedures, suggesting a more efficient surgical skill acquisition (Haque and Srinivasan 2006). Likewise, VMR has been used as a technology for training and simulation of responses to disaster events, thereby improving the field of disaster medicine (Gout et al. 2020). This successful uptake of VMR in medicine likely emerges due to the unfeasibility in replicating real life situations (e.g., response to hurricanes in disaster medicine) as well as the high-risk situations (e.g., delicate surgeries) that are life-threatening to the patient and require unprecedented training to the clinician in lower stakes training contexts (i.e., simulations rather than real life). Furthermore, VMR improves the learning of tasks that require spatial and visual memory, observation, as well as control of emotional responses in stressful conditions (Jensen and Konradsen 2018). Importantly, autistic children have been described as having positive engagement with VMR applications in educational settings (Kandalaft et al. 2013; Strickland et al. 1996), suggesting that VMR can be used in a wide range of contexts and function as an inclusive tool for the education of students with and without special needs (but see discussion on 'Potential misuses of VMR' below). Therefore, VMR has the potential to become an important and inclusive educational tool in our century (Hoffman and Vu 1997). In fact, VMR has recently been used for the teaching and learning of biology, with positive outcomes.

\section{VMR uses in biology education}

While VMR in education has gained exponential attention of the academic community, VMR in biology has advanced at a slower pace, comprising $\sim 5 \%$ of academic publications in the field (Fig. 2a). Nonetheless, VMR has gained important applications in both secondary and tertiary education biology courses (de Jong et al. 2013; Makransky et al. 2016; Poland et al. 2003; Thisgaard and Makransky 2017). A number of VMR applications attempt to reproduce the laboratory environment to students with otherwise no access to laboratory facilities, with demonstrated benefits over traditional lectures (see e.g., Labster; Bonde et al. 2014). Other VMR applications were designed to give the students an immersive experience of more specific biological processes such as cell structure (McClean et al. 1999), spatial orientation (Moritz and Meyer 2004), and vision formation in animals (Gochman et al. 2019). Students report higher engagement and learning outcomes with immersive experiences offered by VMR applications, which is encouraging for the use of VMR in biology education (Makransky et al. 2019; Makransky et al. 2016; Mikropoulos et al. 2003; Mikropoulos and Natsis 2011; Shim et al. 2003) (Fig. 2b). For example, Moritz and Meyer 2004 designed an immersive interactive VMR platform for visualisation and teaching of conformation and geometry of protein crystallographic structures, whereby the test group was able to identify characteristics and regions in the samples that were obfuscated in non-immersive programs (Moritz and Meyer 2004). More recently, VMR has been implemented in biology classes teaching digestion, with seemingly positive results measured by higher cognitive thinking as well as attitudes towards VMR use (Choi and Kim 2020). Moreover, a recent VMR application to train undergraduate students on the use of light microscopes has proven to be successful as well as desirable as means to enhance students' learning experiences (Paxinou et al. 2020). Younger students also seem to benefit from the use of VMR education in biology, given that a cohort of ninth-graders that experienced traditional learning materials supplemented by VMR displayed improved analysis skills and learning attitudes towards biology (Weng et al. 2020). Thus, innovative curricula that harness the power of new technologies can provide significant benefits to 
the teaching and learning of biology (Eastwood and Sadler 2013; Sadler et al. 2015).

VMR applications could help learning and teaching of ecology by simulating field expeditions in which students have to identify plants and/or animals in virtual reality, as in non-immersive virtual field trips developed previously (e.g., Dunleavy et al. 2009; Spicer and Stratford 2001). Students have in fact reported that non-immersive virtual field trips provide a useful complement to the real field trip and could be a powerful tool to prepare and revise real field trips (Spicer and Stratford 2001). This could also complement units of taxonomy of plants and animals as well as provide virtual field experience to the student prior to the real task, thereby amalgamating students' learning experience. In VMR, immersive scenarios could include representative environments from different ecosystems (e.g., Amazon rainforest, tundra, desert) in which the aim is to identify the greater number of plant species as well as the morphological traits that are shared amongst species.

It is important to mention that virtual systems have been developed to explore all aspects of biology education. For instance, previous digital material has been designed for teaching and learning of astrobiology (for instance in the Habitable Worlds platform; Horodyskyj et al. 2018), although not yet in the fully immersive platform of VMR. Habitable Worlds allows students to experience an inquiry-driven learning environment designed to enhance students' learning outcomes on science through observation and modelling of virtual systems (Horodyskyj et al. 2018). The results are promising as more than $70 \%$ of students had grades average or higher, and student engagement significantly increased compared to benchmark. As such, Habitable Worlds provides some guidelines for the design of digital platforms that could be transferable to VMR systems, including
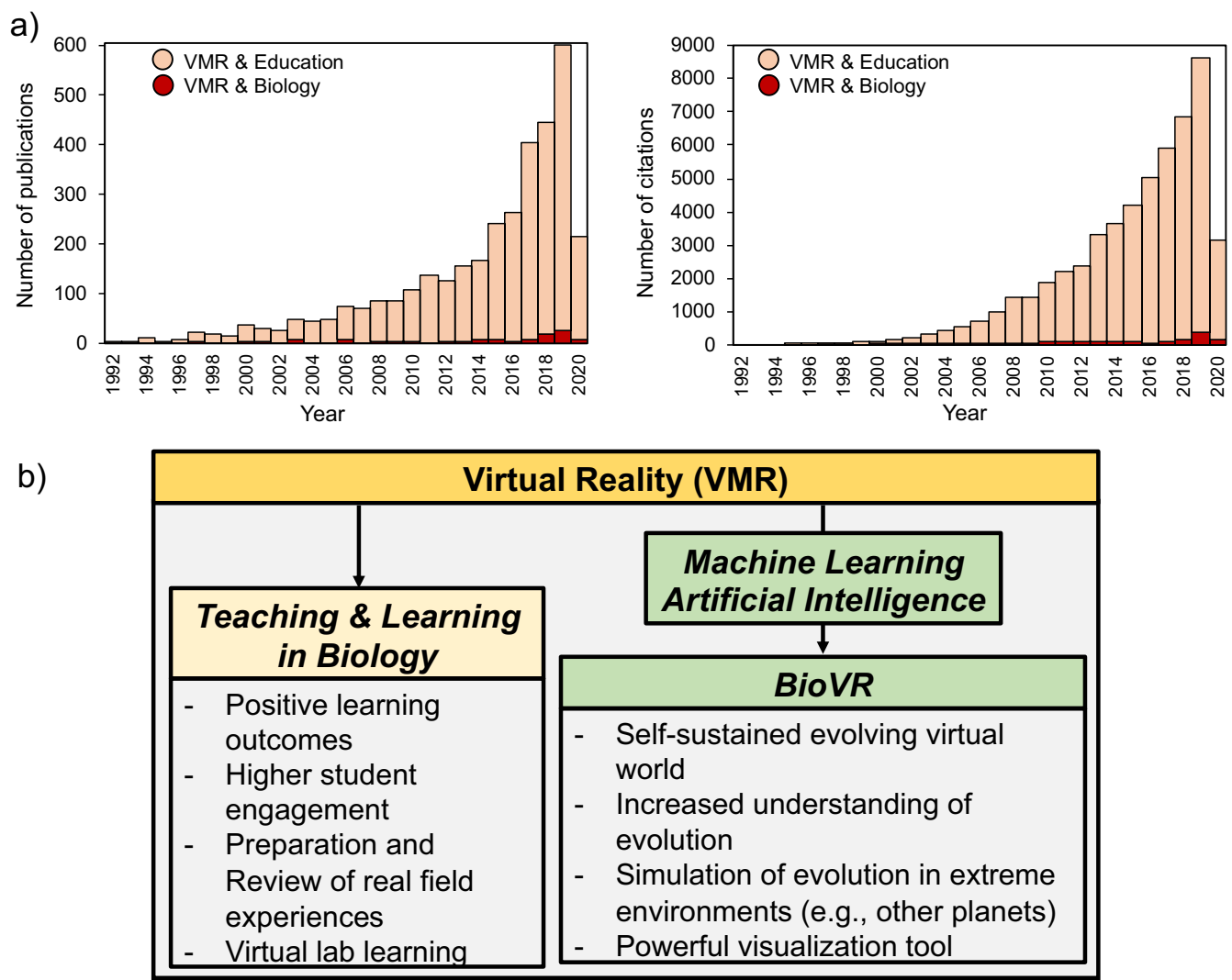

Fig. 2 VMR increasing importance in academic and educational context. a Web of Science Topic query of publications (left) and citations (right) that involves VMR and education (orange) and VMR and biology (red). WoS searches were conducted on 12-May-2020 with search term queries '(virtual AND augmented) reality AND education' or '(virtual AND augmented) reality AND biology'. For each search, reviews and proceedings of conferences were excluded. In total, there were 6443 and 133 papers that fitted the selection criteria, respectively. b Schematic overview of the potential for VMR to impact Biology. On one hand, VMR has increasingly been used for teaching of a variety of topics within Biology. As technology advances, it may be possible to combine other cutting-edge technologies such as Machine Learning and Artificial Intelligent to create a self-sustained evolving virtual world (BiovR) that allows us to gain insights into biological processes 
a) Unsupervised learning

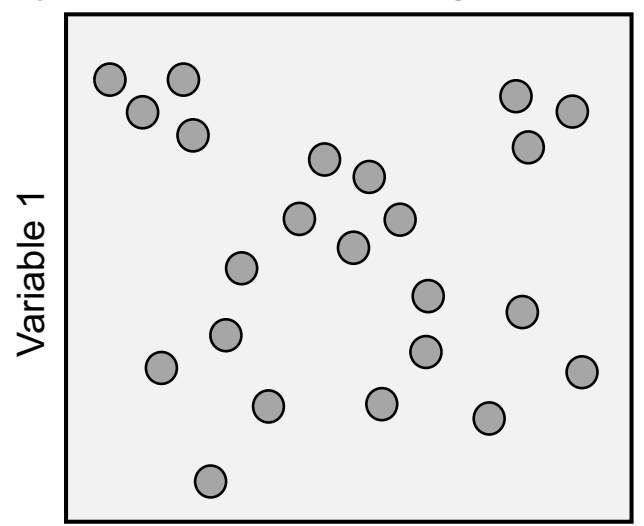

Variable 2

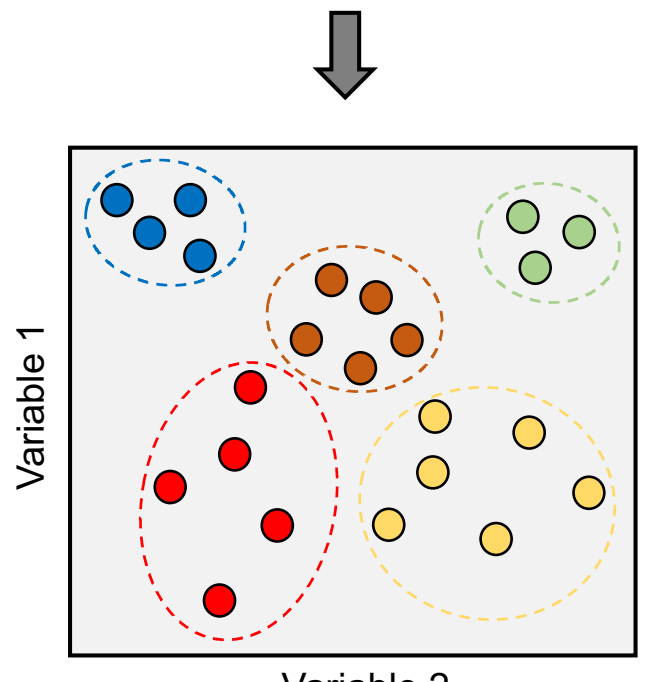

b) Supervised learning

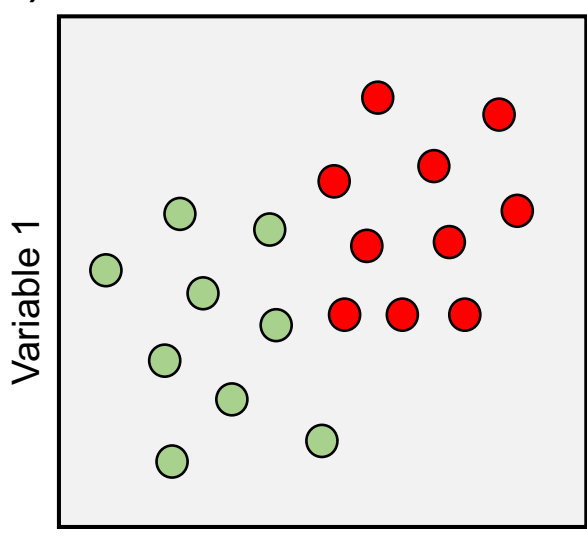

Variable 2

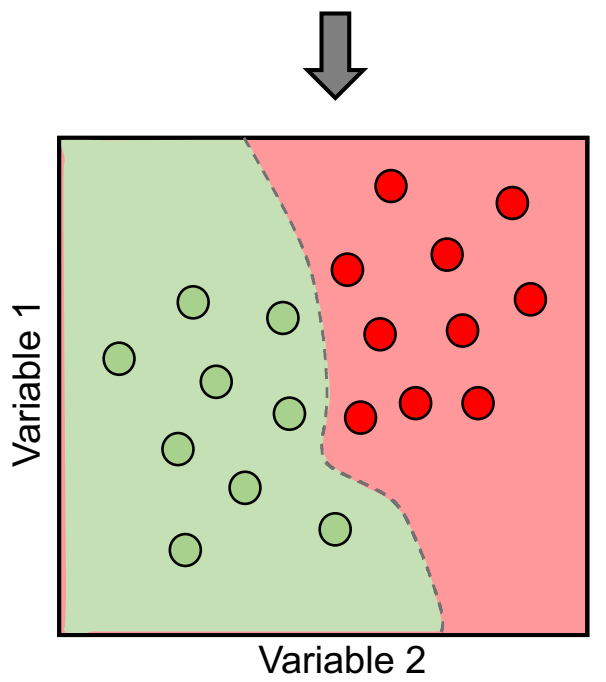

Fig. 3 Supervised and unsupervised machine learning. a Schematic representation of an unsupervised learning model. Unlabelled data is used in unsupervised learning algorithms for clustering. $\mathbf{b}$ Schematic representation of a supervised learning model. Labelled data are used in supervised learning algorithms for classification. Machine learning models can be broadly classified into supervised or unsupervised learning algorithms, depending on the structure of the data (Mitchell et al. 2013) [Note: there are intermediate cases called semi-supervised learning which we will not consider here, see e.g., Zhu and Goldberg 2009 for details]. Unsupervised learning algorithms use data in which the outcome is not yet labelled or identified, and therefore the algorithm cannot ' $k$ now' the outcomes in advance. The algorithm then learns how to classify and predict the outcome from new observations based on the inherent structure of the data at hand. An example of unsupervised learning is the clustering of groups within a dataset. Conversely, supervised learning algorithms uses data in which the outcome is known, and the algorithm learns how to predict the outcome of future observations based on what was learnt from the information and outcomes obtained from previous data. An example of supervised learning is the classification (or prediction, in the case of regression models) of a new observation between two categories based on $n$ number of characteristics or variables

automated feedback. Such feedback accepts a wide range of possible correct answers and automatically returns personalized feedback depending on student submissions (known as Adaptive eLearning Platform 'AeLP'; Horodyskyj et al. 2018). Briefly, AeLP contains a pool of correct answers, which permit activity continuation, and incorrect answers, which automatically recognise that the student failed to complete the task correctly (see Fig. 4 in Horodyskyj et al. 2018 for visual details of the automated feedback pipeline). Importantly, AeLP also incorporates analytical tools for the teacher or instructors, allowing the automated analysis of student performance relative to learning outcomes (Horodyskyj et al. 2018). It would be interesting for future developments of Habitable Worlds to expand the educational content from astrobiology to other subjects within biology, as well as to include VMR experience and compare the performance of students with traditional versus immersive platforms. 


\section{Artificial life: bio-inspired systems and the rise of artificial evolution}

As technological power has increased, researchers and programmers have become progressively more interested in using the virtual world to replicate biological phenomena observed in the real world (e.g., the evolution of artificial life). While few artificial life systems exist, perhaps the most famous example comes from the work of Thomas Ray and the 'Tierra' system (Langton 1997; Langton 1986; Lehman et al. 2018; Ray 1992). The Tierra system simulates artificial life in self-replicating, evolving entities ('algorithms') confined within virtual computer spaces, whereby the entities can be considered as uni- or multi-cellular entities that experience errors in replication analogous to mutations in biological reproduction (Ray 1994; Ray 1992; Thearling and Ray 1994). Instead of solar energy and natural resources as in biological systems, artificial entities compete for central processing unit (CPU) and memory space [analogous to energy and spatial resource, respectively (as described in Ray 1992)]. As a result, artificial Tierra entities become progressively more adapted to exploit one another in order to gain advantage over the use of CPU and memory (Ray 1994; Ray 1992; Ray and Xu 2001; Thearling and Ray 1994). The outcome of this self-sustained virtual evolutionary world is remarkable given that the system evolves differences in entity sizes, ecological specialisation (e.g., parasites) and population dynamic processes (e.g., extinction) (Ray 1992, 1994; Ray and Xu 2001; Shao and Ray 2010). 'Tierra' provides an unprecedented case study to compare and understand how different shapes and forms emerge through evolutionary processes. However, visualisation of evolution in the Tierra system is not straightforward and largely inaccessible to a broader audience due to the highly technical language underlying the system. This poses a significant barrier to biologists with limited computational expertise and is, to some extent, visually unappealing for students of biological sciences and related disciplines. Consequently, it is difficult (though not impossible) to use artificial model systems such as Tierra as an effective educational tool in the classroom while keeping the attention span and interest of students.

In a similar idea pertaining digital evolution but with a student-centric view, there is the development of an evolutionary biology digital platform called Avida (Ofria and Wilke 2004) which has been adapted for educational purposes (Avida-ED) (Abi Abdallah et al. 2020; Pennock 2007; Smith et al. 2016; Speth et al. 2009). AvidaED allows students to visualise and manipulate entities in order to simulate a range of biological and evolutionary processes, including mutation and genetic variation, natural selection and population dynamics (https://avida-ed. msu.edu/curriculum/\#ModelLessons). These topics and associated lessons have emerged through an extensive research program to develop a curriculum proven to be effective at delivering on its learning outcomes (Smith et al. 2016), and thus have increasing potential to become a primary resource worldwide. While extremely powerful, Avida-ED (like Tierra) does not yet integrate the use of VMR. Other games (video-game and computer) have been devised in the early $90 \mathrm{~s}$ with the aim to simulate evolution and give the player a sense of control as to what evolves, how it evolves, and/or when it evolves, including games such as SimLife (Keizer 1993) and SimEarth (Bremer 1993). However, it is difficult to assess the extent to which the rules underpinning the evolutionary nature of the programs were drawn from real-world data, and they lack implementation in a VMR configuration. This is crucial because students and educators respond rationally as well as emotionally to the educational material in the VMR immersive experience, which can accentuate learning (Dunleavy et al. 2009; Harley et al. 2016; de Jong et al. 2013; Riva et al. 2007; Thisgaard and Makransky 2017). Thus, VMR can be an appropriate way to overcome accessibility problems of artificially evolving systems while increasing visual appeal to specialists and general audiences. More broadly, this means that, while students can play and/or manipulate artificial life as required by an educator in a computer room or laptop, students still do so in a context that is detached from the natural world., The programs may overshadow the natural history, which is rooted in explorations, meticulous observations, data collection, and thesis formulation. If only students could immerse themselves in voyages similar to those of the past (e.g., exploring new worlds with organisms bearing adaptations to their unique environments) the naturalist spirit could be kept alive, even if within the realm of the virtual world. But could this be possible?

\section{Can VMR and Artificial Intelligence (AI) revolutionise artificial evolutionary systems?}

The technological advances that allowed VMR to become an accessible tool have also promoted advances in Machine Learning and Artificial Intelligence (AI). Machine Learning involves algorithms that process and learn using huge amounts of data in order to perform a task without necessarily being explicitly programmed to do so (Bishop 2006). AI attempts to simulate human intelligence in machine systems; this includes machine learning but also (bio-inspired) robotics, ethics and philosophy associated with AI development (Russell and Norvig 2002). Importantly, AI advances have recently demonstrated that machines can learn from data beyond human capabilities (Chouard 2016; Gibney 2016). Furthermore, a new area on the interface between VMR and 
AI aims to integrate AI to entities in VMR (Augusto et al. 2013; Laukkanen et al. 2004; Luck and Aylett 2000). As a result, a key question emerges: can we combine Machine Learning and AI with VMR to create a self-sustained evolving virtual world (a 'BioVR')? If so, what would be some advantages of combining VMR with AI?

The answer to the first question is, in our opinion, a sounding 'yes'. We strongly believe, albeit at this stage it is a vision (more than a practical application) that future technological advances have the potential to create an immersive virtual world that reproduces the causes of evolution, which can allow us to visualise and measure how species have evolved, how ecosystems are formed, how species adapt to their environment, and how we can anticipate effects of adverse climatic conditions across ecosystems in our changing world. In a sense, we could become 'virtual naturalists' that explore evolution in a simulated (virtual) world in the same sense that naturalists explore the natural (real) world. This experience could be as close as one could have-living in the 21st century and beyond - of the sense of wonder experienced by the pioneers of evolutionary biology such as Darwin and Wallace in their voyages through South America and the world.

But this is not all: there are concrete identifiable learning benefits that emerge from the immersive student experience of observing evolution in e.g., inaccessible and inhospitable environments, trophic interactions, and many more biological processes without stepping outside the classroom (Learning affordance \#2; Table 1). Moreover, the freedom given to the students within these BioVRs forms the perfect ground for inquiry-based learning and engagement, where the students will observe and explore the environment, measuring and experiencing the virtual environment to inquiry about the underlying virtual biological phenomena (Horodyskyj et al. 2018) (Learning affordance \# 3, Table 1). Ultimately, the BioVR could be used to supplement and stimulate collaborative learning tasks, where students may compare and contrast BioVR evolution and identify similarities (e.g., parallel evolution) and divergences (e.g., specialisation of traits) between virtual entities (Learning affordance \#5; Table 1). The BioVR could then eliminate the need for complex computational expertise (at least from the users' point of view) and provide a fully immersive, artificial world upon which entities evolve following basic principles of biological evolution in our and other planets, while students can explore the environment and learn from their own virtual experience.

Practical implementation of BioVR by experts could in theory be achieved through the following steps:

1. Simulate an artificial 'planet' whereby entities will interact, compete, and evolve. In this artificial planet, the 'biotic' rules are established, such as the basic environmental conditions (e.g., temperature), habitat (e.g., marine vs. terrestrial landscapes), resource distribution and so on (similar in concept to the 'soup' in Tierra and the concept of virtual environments in Luck and Aylett 2000).

2. Design the ancestor entity, defining the rules of reproduction, mutation, and ecological interactions that govern the outcomes of interactions between entities as well as with the environment on the planet. This will likely require that the entities follow theoretical models that relate to trait expression and fitness, as well as fitness changes over the lifespan and through generations (see for example models in Edelaar and Bolnick 2019). We envision that the ancestor entity is the 'building block' for artificial life to evolve in BioVR and without it, the system does not have the evolving entity. The ancestor entity is equivalent to the ancestor species originated on Earth, and is a common feature of artificial life systems (e.g., Ray 1994). In other words, the ancestral entity is the first 'living' inhabitant of the virtual planet. A similar concept of the ancestor entity has already been developed for the Avida-ED system (Smith et al. 2016).

3. Gather a large empirical dataset of environmenttraits-species interactions as a basic starting-point

Table 1 Learning affordances of VMR applications. Adapted from Dalgarno and Lee (2010)

\begin{tabular}{cl}
\hline Learning affordance \\
\hline 1 & Immersive VMR environments can assist on the development of enhanced spatial knowledge of the explored environment \\
2 & $\begin{array}{c}\text { Immersive VMR environments allows for simulated experiences which would be otherwise impractical or impossible to undertake in the real } \\
\text { world }\end{array}$ \\
3 & $\begin{array}{c}\text { Immersive VMR environments can increase intrinsic motivation and engagement due to the potential to generate a personalised experience } \\
4\end{array}$ \\
$\begin{array}{l}\text { Immersive VMR environments can facilitate learning of transferable skills and knowledge from a simulated task to real situations } \\
\text { Immersive VMR environments can be used to facilitate and/or supplement collaborative learning tasks, thereby enriching students' learning } \\
\text { experience }\end{array}$
\end{tabular}

${ }^{a}$ Highlight the learning affordances that are directly achieved with the conceptual BioVR model proposed in this study 
for determining how different species evolve in different ecosystems (e.g., evolutionary convergences, divergences, character displacement)—this could be called 'rules of evolution'. This will allow the system to 'know' which adaptations are more likely to yield fitness advantages in a given environment. For instance, heat tolerance (or traits related to coping with high temperatures) is a likely to increase fitness of populations living in virtual habitats that resemble arid regions. The actual evolution of traits following the 'rule of evolution' will depend on the variability present in the ancestral entity populations and we envisage that, in a BioVR simulation, this parameter can be adjustable according to the purpose or the needs of the virtual world.

One way in which evolutionary rules could be extracted from this dataset is using, for example, supervised learning and/or clustering algorithms (see Fig. 3) to extract general rules as to how species evolve (morphologically and behaviourally) across different environments, commonality between functional traits across species in the same environments, as well as the number, distribution, and behaviour of different species within the same environment. For instance, species living in warm habitats are likely to share similar adaptations to high temperatures and thus, one could expect that virtual entities inhabiting warm virtual habitats should resemble follow similar patterns. Once these rules of evolution are estimated (or guessed) across all habitats of the virtual world, ancestral entities can evolve and differentiate accordingly. Large global scale datasets are already available in the public domain and/or are being collated by scientists (in the case of functional traits), such as for example the WorldClim data with climatic data (past and future) (https:// www.worldclim.org/), NOAA data for marine habitats (https://www.ncdc.noaa.gov/data-access/marineoceandata) and functional traits of species (e.g., TRY for plants https://www.try-db.org/TryWeb/Home.php and CorrDB for some animals https://www.animalgenome.org/cgibin/CorrDB/index). For a broad, large-scale application such as that envisioned here, more data are needed, but there is a general tendency for large datasets to be collated and made available, particularly with the increasing participation of citizen science entries to databases (e.g., iNaturalist (Nugent 2018) and GBIF: http://data. gbif.org/). Importantly, AI/ML will become progressively more important to analyse and gain insights from these data, and it is a point in which we envisioned the integration of VMR and AI/ML in our BioVR concept.

4. Ideally, BioVRs are self-sustained, and thus it would be interesting to have the changes and adaptations in one time point to feed back into the system for the next time point. For example, imagine that a species evolves a remarkable adaptation to convert virtual resource A into B. This transformation should feedback into the system so as to allow new evolutionary rules, perhaps favouring other species to adapt and utilise virtual resource B (which is being produced) instead of virtual resource A (Fig. 4).

5. Given this self-sustained cycle of interaction between entities and the environments, and the iterative system that modulates virtual evolutionary rules, BioVR can become an artificial ecosystem, fully accessible for exploration through VMR in inquiry-based learning quests. This would allow students and researchers to experience and study evolution in this immersive environment, and to compare the outcomes of evolutionary processes within different BioVR environments and across BioVRs with different setups. This can have important effects on learning outcomes since data visualisation is key for understanding biological processes and is an essential component of affective learning (e.g., Karr and Brady 2000). Thus, the use of VMR to create BioVR worlds has the potential to allow VMR to transcend the status of an educational tool that helps learning and teaching in Biology to become the main technology for experiencing and learning about virtual biological phenomena.

We provided these steps in order to quick-start ideas about the practical challenges necessary to realise the conceptual proposition made in this paper. We acknowledge that this is a prototype and understand that experts may have better implementation methods and tools. Having said that, these steps are aimed to foster open discussions that can generate international collaborations which may make it possible for BioVR to reach the classroom as an effective educational tool of the future. One way this could be achieved is by reducing the task at hand, and focusing the idea of BioVR proposed here to a specific topic where considerable amounts of data have been collected. One example is foraging behaviour, where the literature has available information both in terms of environmental responses that affect foraging (e.g., O’brien et al. 1990; Perry and Pianka 1997) as well as the underlying mechanisms of decision-making by animals (e.g., Inglis et al. 2001; Mobbs et al. 2018). It is important to mention that while the idea of BioVRs may seem now allusive, attempts to merge the fields of VMR, artificial life, and AI have been around for decades (Luck and Aylett 2000), with more recent efforts emerging from the astonishing 'boost' in computer power of our generation (Petrović 2018; Zhang et al. 2018). We are also aware 


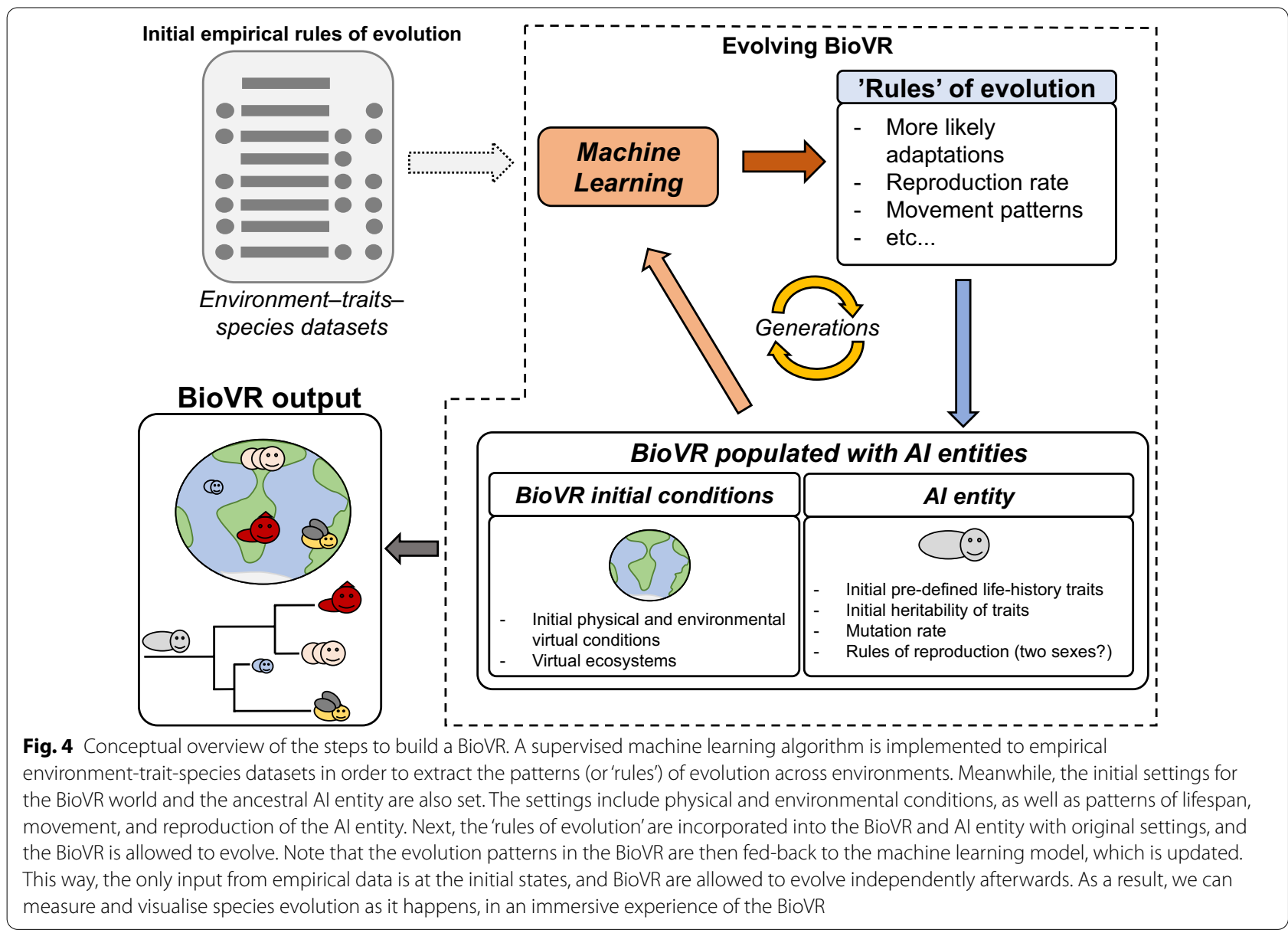

that virtual environments, $\mathrm{AI}$ and semi-autonomous VMR agents have been developed for other purposes such as to direct or assist users with tasks (see e.g., Luck and Aylett 2000). To our knowledge, concepts similar to the one of BioVR as presented in this paper have never been conceptualised let alone tested, which underscores the importance of opening this avenue of communication around the concept of BioVR for future developments that aid biology education. Nevertheless, given the success of artificial evolution systems such as Avida-ED (see above), we believe that an immersive evolutionary software drawing from the BioVR concepts could have significant positive impact in evolution education. Future research and discussion should therefore aim at assessing the feasibility of the concepts proposed here.

\section{A cautionary tale on using VMR: potential misuses}

As with any endeavour, one needs to be aware of the potential negative side-effects of embarking in it. For the voyagers of the past, seasickness was but one of the physical and emotional downsides. For those embarking into the virtual world, there are other constrains that need to considered in future applications of the VMR technologies for teaching and learning in biology, as well as for a future application of the BioVR concept that depends on VMR for an immersive experience. VMR applications are attractive because they contain a wide variety of sensory stimuli that give the participant a sense of presence. However, too many stimuli-such as colours, shapes, characters, movement-can distract the participant and have detrimental effects on learning, a phenomenon that has been acknowledged in the literature and commonly referred to as cognitive overload (Whitelock et al. 2000). A recent study has shown that university students learned less and experienced higher cognitive overload when they experienced a science lab in a fully-mounted VMR headset as opposed to the VMR scenes played on 2D displays, in spite of higher feeling of presence in the VMR scene (Makransky et al. 2019). This suggests that, in some cases, the very same attributes that make VMR attractive can make VMR applications ineffective. Nonetheless, it is possible to mitigate cognitive overload by controlling the information flow that students are exposed to as part of the design of the environment, 
the tasks needed to be completed, as well as the degree of interactivity with the environment at any given point in time (e.g., Andersen et al. 2016; Bharathan et al. 2013; Dorneich et al. 2003; Wang et al. 2019). Other potential negative effects of VMR applications are motion sickness and dizziness caused by the immersive experience, which can preclude appropriate understanding of the learning material and hamper students' achievement of learning outcomes (Davis et al. 2015; McCauley and Sharkey 1992; Ohyama et al. 2007; Palmisano et al. 2017; Regan and Price 1994). For instance, the perception of angular and linear accelerations cause intense motion sickness both in short and long exposure to VMR applications ( $\mathrm{LaVi}$ ola Jr 2000; McCauley and Sharkey 1992; Saredakis et al. 2020; Sharples et al. 2008). Yet, recent studies have demonstrated that motion-sickness can be mitigated or eliminated through appropriate use of VMR design (e.g., how immersive to make the experience) and suitable hardware (e.g., display type) (see e.g., Mittelstaedt, Wacker, and Stelling 2018; Mittelstaedt, Wacker, and Stelling 2019; Weech, Kenny, and Barnett-Cowan 2019). Interestingly, a recent meta-analysis suggested that the feelings of presence and motion-sickness likely trade-off-with higher presence resulting in lower motion-sickness (Weech et al. 2019), supporting the idea that motion-sickness can be mitigated (or eliminated) with thoughtful design and user-experience.

Recent literature provides comprehensive lists of fundamental characteristics of 3D virtual environments and general features that can be adjusted to increase student engagement and learning in virtual systems (see e.g., Dalgarno and Lee 2010; Lindgren et al. 2016; O'Connor and Domingo 2017). In fact, as mentioned above, a series of learning affordances have been identified (Table 1), that have positive influence on student engagement with virtual applications and can ultimately enhance learning (Dalgarno and Lee 2010). Nevertheless, it is key to bear in mind the importance of careful design and testing of new VMR applications prior to implementation in the classroom in order to mitigate potential cognitive overload and/or motion sickness, which could significantly hamper learning (Dalgarno and Lee 2010). Future studies will provide more detailed evidence-based guidelines to build effective VMR applications that maximise educational potential while minimising negative effects of VMR misuse in standard classroom applications as well as eventually, in the BioVR (Akçayır and Akçayır 2017; Dunleavy et al. 2009).

\section{Conclusions}

Almost two centuries ago, Charles Darwin and Alfred Russell Wallace independently boarded expeditions to remote corners of the world, using the science of natural history to make observations, collect data, and ultimately, generate the knowledge foundation for our understanding of the evolution of life on Earth. Today, the fast pace of our societies, the connectivity created by internet and airplanes, and the technological advances at our fingertips have almost completely extinguished the long distant voyages to virgin parts of the world. This has not only put a constraint on the experiences that are available to naturalists, but also changed the way in which natural history as a science is perceived and valued. But perhaps such technological progress does not have to extinguish the naturalist spirit altogether. In this essay, we have provided a visionary-albeit yet not possible-perspective on the future of natural history in teaching and learning of evolutionary biology. We believe that the pieces necessary to achieve this vision are not as far-fetched as one may think. Importantly, the concepts proposed here are not just theoretical, but could have tangible benefits for educators and students of evolutionary biology. As mentioned above, the use of new technologies and innovative applications can provide better learning outcomes and student experiences in face-to-face, blended, and distance learning contexts by amalgamating biological principles in immersive classrooms. This is particularly important in our Covid19 world, where training and learning has shifted almost instantaneously to online and/or distance learning. Given the characteristics of VMR mentioned above, VMR applications have the potential to become one of the most effective tools to overcome social distancing and social isolation while maintaining adequate learning potential across subjects (Singh et al. 2020). In fact, a recent study showed that pre-graduation medical training, disrupted during Covid19, greatly benefited from and was evaluated favourably by students (De Ponti et al. 2020). Thus, overall, the increasing use of VMR has the potential to sustain learning in biology, medicine, and across the realm of STEMM subjects even during global pandemics. We can envision a future where virtual voyagers explore the hidden corners of the virtual world to learn and, perhaps, generate new understanding about the evolution of life.

\section{Abbreviations \\ VR: Virtual reality; AR: Augmented reality; MR: Mixed reality; VMR: Wrapper term which includes virtual, mixed, and augmented reality.}

\section{Acknowledgements \\ We would like to thank editors and anonymous reviewers for insightful com- ments that improved readability of our manuscript. In particular, we would like to thank Reviewer \#1 whose comments made the entire peer-review a stimulating and productive process. We would like to acknowledge Lucy C. Kerr for kindly proof-reading the final version of this manuscript.}

\section{Authors' contributions}

JM reviewed the literature and conceptualised BioVR. JM and FP wrote, revised. Both authors read and approved the final manuscript. 


\section{Funding}

This study was not funded by any funding agency.

\section{Declarations}

\section{Competing interests}

The authors have no competing interests to declare.

\section{Author details}

${ }^{1}$ School of Biological Sciences, University of Aberdeen, Zoology Building, Tillydrone Ave, AB24 2TZ Aberdeen, UK. ²Department of Biological Sciences, Macquarie University, North Ryde, NSW 2109, Australia.

Received: 16 February 2021 Accepted: 19 May 2021 Published online: 28 May 2021

\section{References}

Abi Abdallah DS, Fonner CW, Lax NC, Babeji MR, Palé FA. Evaluating the Use of avida-ed digital organisms to teach evolution \& natural selection. Am Biol Teach. 2020;82(2):114-9. https://doi.org/10.1525/abt.2020.82.2.114.

Akçayır M, Akçayır G. Advantages and challenges associated with augmented reality for education: A systematic review of the literature. Educ Res Rev. 2017;20:1-11. http://www.sciencedirect.com/science/article/pii/S1747 $938 \times 16300616$

Andersen SAW, Mikkelsen PT, Konge L, Cayé-Thomasen P, Sørensen MS. The effect of implementing cognitive load theory-based design principles in virtual reality simulation training of surgical skills: a randomized controlled trial. Adv Simul Springer. 2016;1(1):20.

Augusto JC, Callaghan V, Cook D, Kameas A, Satoh I. Intelligent Environments: a manifesto. Human-centric Comput Inf Sci. 2013;3(1):12. https://doi. org/10.1186/2192-1962-3-12.

Barbot B, Kaufman JC. What makes immersive virtual reality the ultimate empathy machine? Discerning the underlying mechanisms of change. Comput Human Behav. 2020;1:106431.

Bharathan R, Vali S, Setchell T, Miskry T, Darzi A, Aggarwal R. Psychomotor skills and cognitive load training on a virtual reality laparoscopic simulator for tubal surgery is effective. Eur J Obstet Gynecol Reprod Biol Elsevier. 2013;169(2):347-52

Bishop CM. Pattern recognition and machine learning. Jordan M, Kleinberg J, Scholkopf B, editors. Cambridge: Springer Science Business Media; 2006.

Bonde MT, Makransky G, Wandall J, Larsen MV, Morsing M, Jarmer H, et al. Improving biotech education through gamified laboratory simulations. Nat Biotechnol. 2014;32(7):694-7. https://doi.org/10.1038/nbt.2955.

Bremer M. SimEarth: the living planet. Ocean Software; 1993.

Brunette ES, Flemmer RC, Flemmer CL. A review of artificial intelligence. 2009 4th Int. Conf. Auton. Robot. Agents. IEEE; 2009. p. 385-92.

Choi S, Kim H-B. Application and Effects of VR-Based Biology Class Reflecting Characteristics of Virtual Reality. J Korean Assoc Sci Educ The Korean Association for Science Education. 2020;40(2):203-16.

Chouard T. The Go files: Al computer wraps up 4-1 victory against human champion. Nat. News. 2016.

Cummings JJ, Bailenson JN. How immersive is enough? A meta-analysis of the effect of immersive technology on user presence. Media Psychol Taylor Francis. 2016:19(2):272-309.

Dalgarno B, Lee MJW. What are the learning affordances of 3-D virtual environments? Br J Educ Technol. 2010;41(1):10-32. https://doi.org/10.1111/j. 1467-8535.2009.01038.x.

Davies AG, Crohn NJ, Treadgold LA. Can virtual reality really be used within the lecture theatre? BMJ Simul. Technol. Enhanc. Learn. 2019;5(4):234 LP-235. http://stel.bmj.com/content/5/4/234.abstract.

Davis S, Nesbitt K, Nalivaiko E. Comparing the onset of cybersickness using the Oculus Rift and two virtual roller coasters. Proc. 11th Australas. Conf. Interact. Entertain. (IE 2015). 2015. p. 30.

de Jong T, Linn MC, Zacharia ZC. Physical and Virtual Laboratories in Science and Engineering Education. Science (80). 2013;340(6130):305 LP_-308. http://science.sciencemag.org/content/340/6130/305.abstract.
Dorneich MC, Whitlow SD, Ververs PM, Rogers WH. Mitigating cognitive bottlenecks via an augmented cognition adaptive system. SMC'03 Conf. Proceedings. 2003 IEEE Int. Conf. Syst. Man Cybern. Conf. Theme-System Secur. Assur. (Cat. No. 03CH37483). IEEE; 2003. p. 937-44.

Dunleavy M, Dede C, Mitchell R. Affordances and limitations of immersive participatory augmented reality simulations for teaching and learning. J Sci Educ Technol. 2009;18(1):7-22. https://doi.org/10.1007/ s10956-008-9119-1.

Eastwood JL, Sadler TD. Teachers'implementation of a game-based biotechnology curriculum. Comput Educ. 2013;66:11-24. http://www.scien cedirect.com/science/article/pii/S0360131513000328.

Edelaar P, Bolnick DI. Appreciating the multiple processes increasing individual or population fitness. Trends Ecol Evol Elsevier. 2019;34(5):435-46.

Gibney E. Google Al algorithm masters ancient game of Go. Nat News. 2016;529(7587):445.

Gochman SR, Morano Lord M, Goyal N, Chow K, Cooper BK, Gray LK, et al. Tarsier Goggles: a virtual reality tool for experiencing the optics of a dark-adapted primate visual system. Evol Educ Outreach. 2019;12(1):9. https://doi.org/10.1186/s12052-019-0101-6.

Gout L, Hart A, Houze-Cerfon C-H, Sarin R, Ciottone GR, Bounes V. Creating a novel disaster medicine virtual reality training environment. Prehosp Disaster Med. 2020;35(2):25-8.

Haque S, Srinivasan S. A meta-analysis of the training effectiveness of virtual reality surgical simulators. IEEE Trans Inf Technol Biomed. 2006;10(1):51-8.

Harley JM, Poitras EG, Jarrell A, Duffy MC, Lajoie SP. Comparing virtual and location-based augmented reality mobile learning: emotions and learning outcomes. Educ Technol Res Dev. 2016;64(3):359-88. https://doi. org/10.1007/s11423-015-9420-7.

Heilig ML. Sensorama simulator. Google Patents; 1962.

Hoffman H, Vu D. Virtual reality: teaching tool of the twenty-first century? Acad. Med. University of California, San Diego, School of Medicine, La Jolla, USA. hhoffman@ucsd.edu; 1997;72(12):1076-81. http://europ epmc.org/abstract/MED/9435714.

Horodyskyj LB, Mead C, Belinson Z, Buxner S, Semken S, Anbar AD. Habitable Worlds: Delivering on the Promises of Online Education. Astrobiology Mary Ann 2018;18(1):86-99. https://doi.org/10.1089/ast.2016.1550.

Inglis IR, Langton S, Forkman B, Lazarus J. An information primacy model of exploratory and foraging behaviour. Anim Behav Elsevier. 2001;62(3):543-57.

Jensen L, Konradsen F. A review of the use of virtual reality head-mounted displays in education and training. Educ Inf Technol Springer. 2018;23(4):1515-29.

Jerald J, Giokaris P, Woodall D, Hartbolt A, Chandak A, Kuntz S. Developing virtual reality applications with Unity. 2014 IEEE Virtual Real. IEEE; 2014 pp. $1-3$.

Kandalaft MR, Didehbani N, Krawczyk DC, Allen TT, Chapman SB. Virtual reality social cognition training for young adults with high-functioning autism. J Autism Dev Disord Springer. 2013;43(1):34-44.

Karr TL, Brady R. Virtual biology in the CAVE. Trends Genet. 2000;16(5):231-2. https://doi.org/10.1016/S0168-9525(00)01996-X.

Keizer G. Simlife: life goes on and on and on. Omni General Media International Inc. 1993:15(4):12-3.

Kish LB. Moore's law and the energy requirement of computing versus performance. IEEE Proc. - Circuits, Devices Syst. 2004;151(2):190-4.

Kotsiantis SB, Zaharakis ID, Pintelas PE. Machine learning: a review of classification and combining techniques. Artif Intell Rev Springer. 2006;26(3):159-90.

LaViola JJ Jr. A discussion of cybersickness in virtual environments. ACM Sigchi Bull. ACM New York, NY, USA; 2000;32(1):47-56.

Langton CG. Studying artificial life with cellular automata. Phys D Nonlinear Phenom. 1986;22(1):120-49. http://www.sciencedirect.com/science/ article/pii/016727898690237X.

Langton CG. Artificial life: An overview. Massachussets, USA: Mit Press; 1997.

Laukkanen S, Karanta I, Kotovirta V, Markkanen J, Rönkkö J. Adding intelligence to virtual reality. Proc. 16th Eur. Conf. Artif. Intell. Citeseer; 2004. p. $1136-41$.

Ledermann F, Schmalstieg D. APRIL: a high-level framework for creating augmented reality presentations. IEEE; 2005.

Lehman J, Clune J, Misevic D. The surprising creativity of digital evolution. Artif. Life Conf. Proc. MIT Press; Massachussets, USA, 2018. p. 55-6. 
Lindgren R, Tscholl M, Wang S, Johnson E. Enhancing learning and engagement through embodied interaction within a mixed reality simulation. Comput Educ. 2016;95:174-87. http://www.sciencedirect.com/science/ article/pii/S036013151630001X.

Lombart C, Millan E, Normand J-M, Verhulst A, Labbé-Pinlon B, Moreau G. Effects of physical, non-immersive virtual, and immersive virtual store environments on consumers' perceptions and purchase behavior. Comput Human Behav. 2020;1:106374.

Luck M, Aylett R. Applying artificial intelligence to virtual reality: Intelligent virtual environments. Appl Artif Intell. 2000;14(1):3-32. https://doi.org/ 10.1080/088395100117142.

Makransky G, Terkildsen TS, Mayer RE. Adding immersive virtual reality to a science lab simulation causes more presence but less learning. Learn Instr. 2019;60:225-36.

Makransky G, Thisgaard MW, Gadegaard H. Virtual simulations as preparation for lab exercises: assessing learning of key laboratory skills in microbiology and improvement of essential non-cognitive skills. PLoS ONE 2016;11(6): e0155895. https://doi.org/10.1371/journal.pone.01558 95.

Mazuryk T, Gervautz M. Virtual reality-history, applications, technology and future. Citeseer; 1996.

McCauley ME, Sharkey TJ. Cybersickness. Perception of Self-Motion in Virtual Environments. Presence Teleoperators Virtual Environ. MIT Press, Massachussets; 1992;1 (3):pp. 311-8. https://doi.org/10.1162/pres.1992.1.3.311.

McClean PE, Slator BM, White AR. The Virtual Cell: An Interactive, Virtual Environment for Cell Biology. EdMedia + Innov. Learn. Association for the Advancement of Computing in Education (AACE): 1999. pp. 1442-3.

Mikropoulos TA, Natsis A. Educational virtual environments: A ten-year review of empirical research (1999-2009). Comput Educ. 2011;56(3):769-80. http://www.sciencedirect.com/science/article/pii/S0360131510003052.

Mikropoulos TA, Katsikis A, Nikolou E, Tsakalis P. Virtual environments in biology teaching. J. Biol. Educ. Routledge; 2003 Sep 1;37(4):176-81. https://doi. org/10.1080/00219266.2003.9655879.

Milgram P, Takemura H, Utsumi A, Kishino F. Augmented reality: a class of displays on the reality-virtuality continuum. Proc.SPIE 1995. https://doi. org/10.1117/12.197321.

Mitchell RS, Michalski JG, Carbonell TM. An artificial intelligence approach. Berlin: Springer; 2013.

Mittelstaedt J, Wacker J, Stelling D. Effects of display type and motion control on cybersickness in a virtual bike simulator. Displays. 2018;51:43-50.

Mittelstaedt JM, Wacker J, Stelling D. VR aftereffect and the relation of cybersickness and cognitive performance. Virtual Real. 2019:23(2):143-54

Mobbs D, Trimmer PC, Blumstein DT, Dayan P. Foraging for foundations in decision neuroscience: insights from ethology. Nat Rev Neurosci 2018;19(7):419-27.

Moritz E, Meyer J. Interactive 3D protein structure visualization using virtual reality. In: Proceedings. Fourth IEEE Symp. Bioinforma. Bioeng. 2004. p. 503-7.

Naimark M. Elements of real-space imaging: a proposed taxonomy. Stereosc. Displays Appl. II. International Society for Optics and Photonics; 1991. pp. 169-79.

Nugent J. iNaturalist: citizen science for 21st-century naturalists. Sci Scope National Science Teachers Association. 2018:41(7):12.

Ofria C, Wilke CO. Avida: A software platform for research in computational evolutionary biology. Artif Life. 2004;10(2):191-229.

Ohyama S, Nishiike S, Watanabe H, Matsuoka K, Akizuki H, Takeda N, et al. Autonomic responses during motion sickness induced by virtual reality. Auris Nasus Larynx. 2007;34(3):303-6. http://www.sciencedirect.com/ science/article/pii/S0385814607000223.

O'Connor EA, Domingo J. A practical guide, with theoretical underpinnings, for creating effective virtual reality learning environments. J. Educ. Technol. Syst. SAGE Publications Sage CA: Los Angeles, CA; 2017;45(3):343-64.

O'brien WJ, Browman HI, Evans BI. Search strategies of foraging animals. Am Sci. 1990;78(2):152-60

Palmisano S, Mursic R, Kim J. Vection and cybersickness generated by headand-display motion in the Oculus Rift. Displays. 2017:46:1-8.

Paxinou E, Panagiotakopoulos CT, Karatrantou A, Kalles D, Sgourou A. Implementation and evaluation of a three-dimensional virtual reality biology lab versus conventional didactic practices in lab experimenting with the photonic microscope. Biochem Mol Biol Educ. 2020;48(1):21-7. https://doi.org/10.1002/bmb.21307.
Pennock RT. Learning evolution and the nature of science using evolutionary computing and artificial life. McGill J Educ Citeseer. 2007:42(2):211.

Perry G, Pianka ER. Animal foraging: past, present and future. Trends Ecol Evol. 1997;12(9):360-4.

Petrović VM. Artificial Intelligence and Virtual Worlds-Toward Human-Level Al Agents. IEEE Access. 2018;6:39976-88.

Poland R, Velle L, Nichol J. The Virtual Field Station (VFS): using a virtual reality environment for ecological fieldwork in A-Level biological studiesCase Study 3. Br J Educ Technol. 2003;34(2):215-31. https://doi.org/10. $1111 / 1467-8535.00321$

De Ponti R, Marazzato J, Maresca AM, Rovera F, Carcano G, Ferrario MM. Pre-graduation medical training including virtual reality during COVID-19 pandemic: a report on students' perception. BMC Med Educ. 2020;20(1):332. https://doi.org/10.1186/s12909-020-02245-8.

Ray TS. Evolution, complexity, entropy and artificial reality. Phys D Nonlinear Phenom. 1994;75(1):239-63. http://www.sciencedirect.com/science/ article/pii/0167278994902860.

Ray TS, Xu C. Measures of evolvability in Tierra. Artif Life Robot. 2001:5(4):211-4. https://doi.org/10.1007/BF02481504.

Ray TS. Evolution, ecology and optimization of digital organisms. Citeseer; 1992.

Regan EC, Price KR. The frequency of occurrence and severity of side-effects of immersion virtual reality. Aviat. Space. Environ. Med. Aerospace Medical Assn; 1994

Riva G, Mantovani F, Capideville CS, Preziosa A, Morganti F, Villani D, et al. Affective interactions using virtual reality: the link between presence and emotions. Cyber Psychol Behav. 2007;10(1):45-56.

Robinett W. Synthetic experience: a proposed taxonomy. Presence Teleoperators Virtual Environ 1992;1(2):229-47.

Russell S, Norvig P. Artificial intelligence: a modern approach. Upper Saddle River New Jersey: Pearson Education; 2002.

Sadler TD, Romine WL, Menon D, Ferdig RE, Annetta L. Learning Biology Through Innovative Curricula: A Comparison of Game- and Nongame-Based Approaches. Sci. Educ. John Wiley \& Sons, Ltd; 2015 Jul 1;99(4):696-720. https://doi.org/10.1002/sce.21171.

Saredakis D, Szpak A, Birckhead B, Keage HAD, Rizzo A, Loetscher T. Factors associated with virtual reality sickness in head-mounted displays: a systematic review and meta-analysis. Front. Hum. Neurosci. Frontiers Media SA; 2020;14.

Serino M, Cordrey K, McLaughlin L, Milanaik RL. Pokémon Go and augmented virtual reality games: a cautionary commentary for parents and pediatricians. Curr Opin Pediatr Wolters Kluwer. 2016:28(5):673-7.

Shao J, Ray TS. Maintenance of Species Diversity by Predation in the Tierra System. ALife. 2010. p. 533-40.

Sharples S, Cobb S, Moody A, Wilson JR. Virtual reality induced symptoms and effects (VRISE): Comparison of head mounted display (HMD), desktop and projection display systems. Displays Elsevier. 2008;29(2):58-69.

Sheridan TB. Musings on telepresence and virtual presence. Presence Teleoperators Virtual Environ MIT Press. 1992;1 (1):120-6.

Shim K-C, Park J-S, Kim H-S, Kim J-H, Park Y-C, Ryu H-I. Application of virtual reality technology in biology education. J Biol Educ. 2003;37(2):71-4. https://doi.org/10.1080/00219266.2003.9655854.

Shim KC, Kim HS, Park YC. Application of Multi-media in Biology Education, Summer Program of Korean Society of Biology Education. null, editor.; 2000.

Singh RP, Javaid M, Kataria R, Tyagi M, Haleem A, Suman R. Significant applications of virtual reality for COVID-19 pandemic. Diabetes Metab Syndr Clin Res Rev Elsevier. 2020;14(4):661-4.

Slater M. A note on presence terminology. Presence Connect Citeseer. 2003:3(3):1-5.

Smith JJ, Johnson WR, Lark AM, Mead LS, Wiser MJ, Pennock RT. An Avida-ED digital evolution curriculum for undergraduate biology. Evol Educ Outreach Springer. 2016;9(1):1-11.

Speth EB, Long TM, Pennock RT, Ebert-May D. Using Avida-ED for teaching and learning about evolution in undergraduate introductory biology courses. Evol Educ Outreach Springer. 2009;2(3):415-28.

Spicer J, Stratford J. Student perceptions of a virtual field trip to replace a real field trip. J. Comput. Assist. Learn. 2001 Dec 1:17:345-54.

Strickland D, Marcus LM, Mesibov GB, Hogan K. Brief report: Two case studies using virtual reality as a learning tool for autistic children. J Autism Dev Disord Springer. 1996;26(6):651-9. 
Sulloway FJ. Darwin's conversion: The Beagle voyage and its aftermath. J Hist Biol Springer. 1982;15(3):325-96.

Thearling K, Ray TS. Evolving multi-cellular artificial life. Artif. Life IV. 1994. p. 283-8.

Thisgaard M, Makransky G. Virtual Learning simulations in high school: effects on cognitive and non-cognitive outcomes and implications on the development of STEM academic and career choice. Front Psychol. 2017. https://doi.org/10.3389/fpsyg.2017.00805.

Veletsianos G. Emerging technologies in distance education. New York: Athabasca University Press; 2010.

Waldrop MM. The chips are down for Moore's law. Nat News. 2016;530(7589):144.

Wang D, Yang Q, Abdul A, Lim BY. Designing theory-driven user-centric explainable Al. Proc. 2019 CHI Conf. Hum. factors Comput. Syst. 2019. p. 1-15.

Weech S, Kenny S, Barnett-Cowan M. Presence and cybersickness in virtual reality are negatively related: a review. Front Psychol. 2019. https://doi. org/10.3389/fpsyg.2019.00158.

Weng C, Otanga S, Christianto SM, Chu RJ-C. Enhancing students' biology learning by using augmented reality as a learning supplement. J Educ Comput Res. 2020;58(4):747-70.

Wexelblat A. Virtual reality: applications and explorations. Oxford: Academic Press; 2014.

Whitelock D, Romano D, Jelfs A, Brna P. Perfect presence: What does this mean for the design of virtual learning environments? Educ. Inf Technol. 2000:5(4):277-89.

Yoh M-S. The Reality of Virtual Reality. Proc. Seventh Int. Conf. Virtual Syst. Multimed. USA: IEEE Computer Society; 2001. p. 666.
Zhang Z, Cao B, Guo J, Weng D, Liu Y, Wang Y. Inverse Virtual Reality: Intelligence-Driven Mutually Mirrored World. 2018 IEEE Conf. Virtual Real. 3D User Interfaces. 2018. p. 735-6.

Zhu X, Goldberg AB. Introduction to semi-supervised learning. Synth Lect Artif Intell Mach Learn. 2009;3(1):1-130.

Zsila A, Orosz G, Bőthe B, Tóth-Király I, Király O, Griffiths M, et al. An empirical study on the motivations underlying augmented reality games: The case of Pokémon Go during and after Pokémon fever. Pers Individ Dif. 2018;133:56-66. http://www.sciencedirect.com/science/article/pii/ S0191886917304117.

\section{Publisher's Note}

Springer Nature remains neutral with regard to jurisdictional claims in published maps and institutional affiliations.
Ready to submit your research? Choose BMC and benefit from:

- fast, convenient online submission

- thorough peer review by experienced researchers in your field

- rapid publication on acceptance

- support for research data, including large and complex data types

- gold Open Access which fosters wider collaboration and increased citations

- maximum visibility for your research: over $100 \mathrm{M}$ website views per year

At BMC, research is always in progress.

Learn more biomedcentral.com/submissions 